\title{
Agenesis of the sphenoid sinus and a single sphenoid sinus: a computed tomography anatomical evaluation
}

\author{
J. Jaworek-Troć1, 2, J.A. Walocha' ${ }^{1}$, M. Lipski', S. Popovchenko', K. Shafarenko', \\ T. Gładysz ${ }^{3}$, P. Depukat ${ }^{1}$, J.J. Zarzecki ${ }^{4}$ R. Chrzan², A. Urbanik², M.P. Zarzecki ${ }^{1}$ \\ ${ }^{1}$ Department of Anatomy, Jagiellonian University Medical College, Krakow, Poland \\ ${ }^{2}$ Department of Radiology, Jagiellonian University Medical College, Krakow, Poland \\ ${ }^{3}$ Department of Dental Surgery, Institute of Dentistry, Jagiellonian University Medical College, Krakow, Poland \\ ${ }^{4}$ Medical University of Silesia, Katowice, Poland
}

[Received: 6 August 2021; Accepted: 1 September 2021; Early publication date: 15 September 2021]

Background: Sphenoid sinuses are pneumatic spaces within the body of the sphenoid bone. Their development begins in the prenatal life and continues until the adulthood. Agenesis of the sphenoid sinuses is a situation in which they are undeveloped. On the other hand, a single sphenoid sinus lacks the presence of the main septum, leading to the formation of a single antrum. Contemporary use of transnasal transsphenoidal approaches for the pituitary surgery, as well as functional endoscopic sinus surgery urges medical professionals to be well acquainted with the aforementioned variant.

Materials and methods: Paranasal sinuses of 300 patients (150 females, 150 males) were evaluated using computed tomography, without the use of contrast medium. Inclusion criteria involved absence of any identifiable pathology within the sphenoid sinuses and age over 18 years. Subgroup analysis involved probing for potential sources of heterogeneity, namely gender.

Results: In the whole research material of 300 patients, agenesis of the sphenoid sinuses was noted in $1 \%$ of the patients. No statistically significant differences were noted between the absence of the sphenoid sinuses and gender ( $p=0.999$ ). A single sphenoid sinus was found in $0.33 \%$ of the patients. There were no statistically significant differences found between the presence of fully developed sphenoid sinuses and gender ( $p=0.498$ ).

Conclusions: Both agenesis of the sphenoid sinuses and a single sphenoid sinus are rare anatomical variants. Adequate planning for transsphenoidal surgeries with preoperative medical imaging is of essence in order to perform a safe and quality procedure. (Folia Morphol 2021; 80, 4: 947-953)

Key words: agenesis, sphenoid sinus, computed tomography, anatomy

\section{INTRODUCTION}

Undoubtedly sphenoid sinuses are an anatomical entity with one of the most variant anatomy, con- cerning namely its septation, proximity to the nearby crucial neurovascular structures, pneumatisation patterns and others [19-27, 34]. Notwithstanding, there

Address for correspondence: Dr. M.P. Zarzecki, MD, Department of Anatomy, Jagiellonian University Medical College, ul. Kopernika 12, 31-034 Kraków, Poland, tel/fax: +48 1242295 11, e-mail: michal.zarzecki@uj.edu.pl

This article is available in open access under Creative Common Attribution-Non-Commercial-No Derivatives 4.0 International (CC BY-NC-ND 4.0) license, allowing to download articles and share them with others as long as they credit the authors and the publisher, but without permission to change them in any way or use them commercially. 
is still a constant need for new reports regarding their variations due to the fact that they are of immense importance namely in functional endoscopic sinus surgery and transnasal transsphenoidal approaches for the pituitary surgery and medical professionals are still poorly acquainted with some of the anatomical features (e.g. the exact parasympathetic pathway of the ethmoid and sphenoid sinuses) [8].

Bilateral intussusception of the nasal mucosa posteriorly, in the direction of the sphenoid bone, is said to be the initial process of sphenoid sinus development, occurring around the $3^{\text {rd }}-4^{\text {th }}$ month of gestation [14, 35]. They resemble recesses (i.e. sphenopalatine recesses) and correspond to the later sphenoid sinus' ostia. The sphenoid sinuses can be noted in the neonates, having approximately $2 \mathrm{~mm}$ in dimension [9]. Nonetheless, their pneumatisation is initiated in the postnatal life, roughly around the $3^{\text {rd }}-4^{\text {th }}$ year, and terminates following the puberty, around the $12^{\text {th }}-16^{\text {th }}$ year of life [36].

The presphenoidal area is the primary site of pneumatisation of the sphenoid sinuses that in due time extends towards the anterior wall of the clivus, at the basisphenoidal area [9]. When a person reaches puberty, their sphenoid sinuses are said to be fully and properly developed; however, the process of pneumatisation might advance outside the body of the sphenoid thus creating recesses of the sphenoid sinus in some individuals [3]. In their recent study, Jaworek-Troć et al. [21] have found that only in 18/296 patients studied via the computed tomography (CT) there were no recesses present. It is said that the pneumatisation of the sphenoid sinuses terminates in the third decade of life of a human, what might be related to the potential aeration of the sphenoid bone even more posteriorly, towards the basis of the occipital bone that coincides with ossification of the spheno-occipital synchondrosis (approximately at the $20^{\text {th }}$ year of age) [36]. Agenesis of the sphenoid sinuses is a situation in which the said anatomical entities do not develop in an individual.

The aim for the current study was to evaluate the prevalence of the agenesis of sphenoid sinuses, as well as single sphenoid sinuses, among Polish adult population and to probe for potential heterogeneity of the results in terms of gender.

\section{MATERIALS AND METHODS}

A total of 300 patients (150 females, 150 males) were included in this retrospective analysis of CT evaluation of paranasal sinuses, conducted at the Department of Medical Imaging, University Hospital in Krakow, Poland. Only patients over 18 years of age with no identifiable pathology in the sphenoid sinuses were deemed eligible for this study. Any head trauma or a surgical intervention in the nasal, orbital or cranial basis region excluded patients from the research group.

A spiral CT scanner (Siemens Somatom Sensation 16) was utilised in a standard procedure, in the option Siemens CARE Dose 4D, in order to obtain images of the paranasal sinuses. No contrast medium was administered to any of the patients. Images in the frontal and sagittal planes were obtained with the secondary reconstruction tool (multiplans reconstruction) from the images in the transverse plane. The medical images were processed with the help of Siemens Volume Wizard diagnostic station.

\section{Ethical approval}

All procedures performed in studies involving human participants were in accordance with the ethical standards of the institutional and/or national research committee and with the 1964 Helsinki declaration and its later amendments or comparable ethical standards. For this type of study, formal consent is not required.

\section{Statistical analysis}

STATISTICA version 13.3 by TIBCO Software Inc. ${ }^{\circledR}$ was used for the statistical analysis in the current study. Fisher's exact test applied whilst probing for potential differences between the agenesis of the sphenoid sinuses and gender. Value of $p<0.05$ was regarded as statistically significant.

\section{RESULTS}

The agenesis of the sphenoid sinuses was noted in 3 patients ( 2 females, 1 male) in the total research group of 300 patients (150 females, 150 males).

No statistically significant differences were found between the agenesis of the sphenoid sinuses and gender ( $p=0.999$, Fisher's exact test). Henceforth, the proportion of developed sphenoid sinuses and their agenesis is approximately similar in both sexes. The prevalence of fully developed sphenoid sinuses was approximately $99 \%$ for both the female and male research groups (Figs. 1-3, Table 1).

A single sphenoid sinus (with no visible main septum dividing the sinus into two antra) was found only 


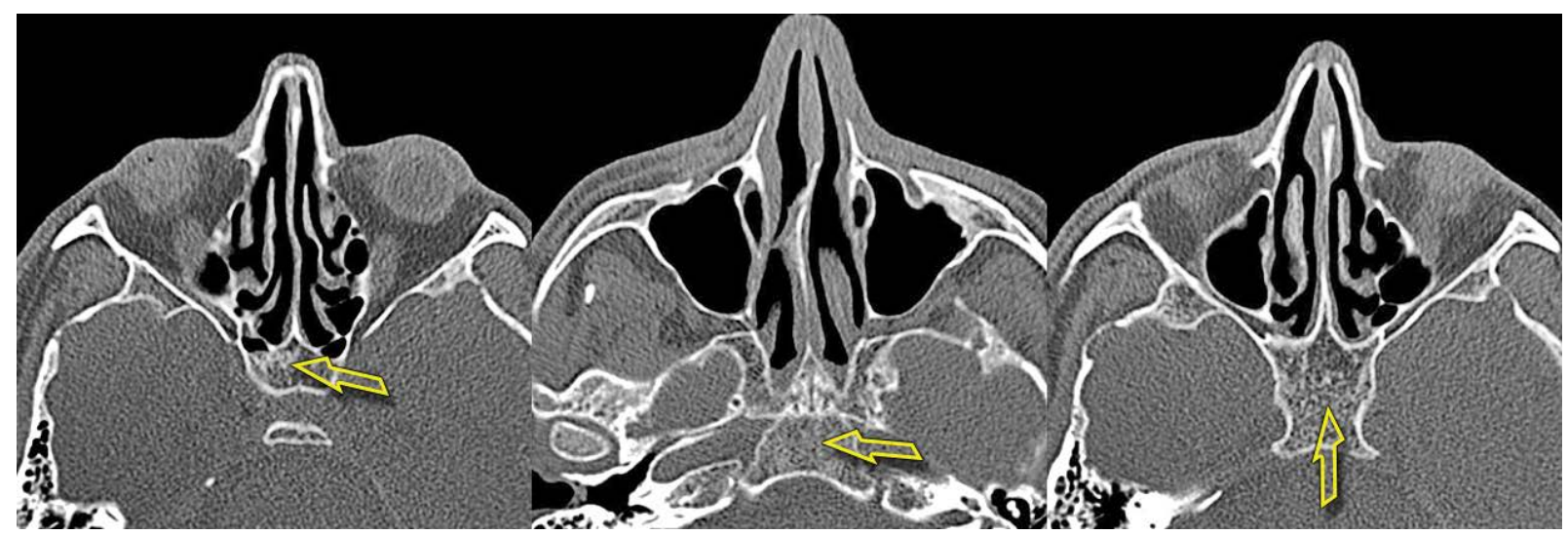

Figure 1. A computed tomography scan of the paranasal sinuses, three sequential images in the transverse plane, taken in a single patient, showing agenesis of the sphenoid sinuses.

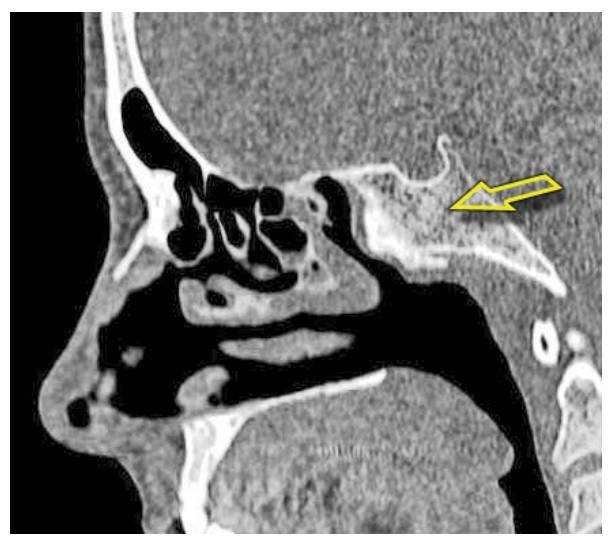

Figure 2. A computed tomography scan of the paranasal sinuses, an image in the sagittal plane. The arrow shows no pneumatisation of the body of the sphenoid bone - agenesis of the sphenoid sinuses.

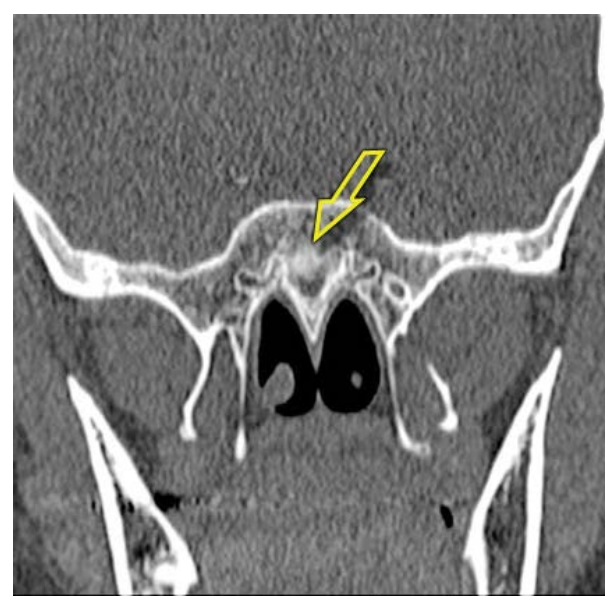

Figure 3. A computed tomography scan of the paranasal sinuses, an image in the frontal plane. The arrow shows no pneumatisation of the body of the sphenoid bone - agenesis of the sphenoid sinuses.
Table 1. Prevalence of the agenesis of the sphenoid sinuses

\begin{tabular}{lcccccc}
\hline & $\mathbf{F}$ & $\mathbf{F \%}$ & $\mathbf{M}$ & $\mathbf{M} \%$ & $\mathbf{F}+\mathbf{M}$ & $\mathbf{F}+\mathbf{M} \%$ \\
\hline Agenetic SS & 2 & $1.33 \%$ & 1 & $0.67 \%$ & 3 & $1 \%$ \\
Developed SS & 148 & $\mathbf{9 8 . 6 7 \%}$ & 149 & $\mathbf{9 9 . 3 3 \%}$ & 297 & $\mathbf{9 9 \%}$ \\
\hline
\end{tabular}

Agenetic SS - agenesis of the sphenoid sinuses; Developed SS - fully developed sphenoid sinuses; $\mathrm{F}$ - number of females; $\mathrm{F} \%$ - the percentage of females; $\mathrm{M}$ - number of males; $\mathrm{M} \%$ — the percentage of males

in 1 female patient $(0.33 \%$ of all the patients). Fully developed sphenoid sinuses (i.e. having at least two antra) were noted in 296 (99.68\%) patients. No statistically significant differences were found between the presence of a single sphenoid sinus or at least two sinuses and gender $(p=0.498$, Fisher's exact test) (Figs. 4, 5).

\section{DISCUSSION}

In the current study, agenesis of the sphenoid sinus was found in $3(1 \%)$ patients in the whole research material of 300 patients.

Earwaker [11] has estimated the frequency of prevalence of undeveloped sphenoid sinuses as $1.625 \%(13 / 800)$ in his CT study of paranasal sinuses, but the research group studied comprised also children (the age range of the patients studied was 12-81). Lower prevalence of the sphenoid sinus agenesis was found by Cakur et al. [7] who estimated it to be approximately $0.26 \%$. The population studied involved patients of Turkish origins.

Different results were obtained by Aydinlioglu and Erdem [5] who did not find any cases of sphenoid sinus agenesis in their research group of 1526 patients (conducted on the CT scans). The said differ- 


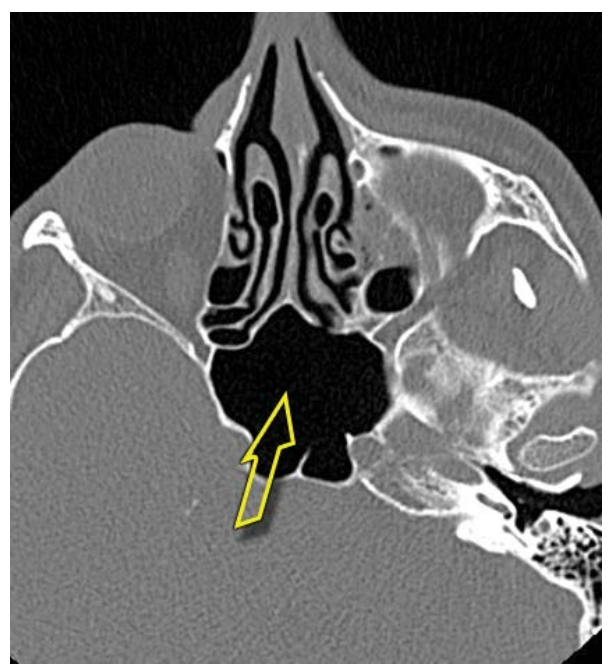

Figure 4. A computed tomography scan of the paranasal sinuses, an image in the transverse plane. A single sphenoid sinus - the main septum is absent.

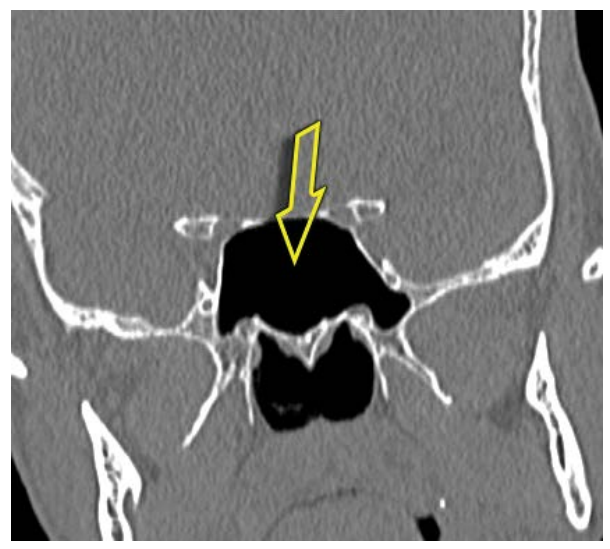

Figure 5. A computed tomography scan of the paranasal sinuses, an image in the frontal plane. A single sphenoid sinus - the main septum is absent.

Table 2. Prevalence of the agenesis of the sphenoid sinuses in the available literature

\begin{tabular}{lc}
\hline Authors (materials and methods) & $\begin{array}{c}\text { Agenesis of the sphenoid } \\
\text { sinuses }\end{array}$ \\
\hline Earwaker (800 CT scans) & $1.625 \%$ \\
Cakur et al. (384 DVCT scans) & $0.26 \%$ \\
Aydinlioglu and Erdem (1526 CT scans) & $0 \%$ \\
Yune et al. (-) & $?$ \\
Anik et al. (-) & $?$ \\
Haktanir et al. (-) & $?$ \\
Degirmenci et al. (-) & $?$ \\
Jaworek-Troć et al. (300 CT scans) & $1 \%$ \\
\hline
\end{tabular}

? - the authors were aware of the said variant, but did not provide a specific numerical value; CT — computed tomography; DVCT — dental volumetric computed tomography ences might possibly be put down to the population studied - the patients originated from Turkey. Yune et al. [37], Anik et al. [2], Haktanir et al. [16] and Degirmenci et al. [9] state that the sphenoid sinus agenesis is a rare finding, but provide no specific details on the matter (Table 2).

The present research did not find any statistically significant differences between gender and agenesis of the sphenoid sinuses $(p=0.999)$. Furthermore, this aspect was not previously investigated by other authors who have identified the aforementioned variant $[7,11]$. Nonetheless, the presence of this variant is rare ( $1 \%$ in the current study) what might account for the lack of the observed differences that ought to be better addressed in studies involving bigger number of patients (counting possibly in thousands).

As shown in the present study, the sphenoid sinus is typically divided by at least one septum into 2 or more antra, whilst the presence of a single developed sphenoid sinus (with the main septum absent) was noted in $0.33 \%$ of all the patients.

Similar prevalence of a single sphenoid sinus was stated by Aydinlioglu and Erdem [5] - 0.13\% (2/1526); however, one of their patients was under 18 years of age (they were 16 years old). Seddighi et al. [29] (in their research group of $64 \mathrm{CT}$ and magnetic resonance imaging [MRI scans]), Abdullah et al. [1] (70 CT scans), and Tan and Ong [33] (cadaveric and endoscopic study of 48 human skulls) did not find a single case of absence of the main septum, which might possibly be put down to the limited number of the sinuses studied. Likewise, Hammer and Radberg [18] state the presence of at least one septum in $100 \%$, which might be related to the diagnostic method used (120 skulls evaluated in X-ray and CT and 103 X-ray images). Battal et al. [6] found the frequency of the absence of the main septum of around $1.3 \%$, but the study group included patients with the conchal (foetal) type of pneumatisation (3 patients), as well as 1 patient in whom not a single septum was noted.

Slightly higher prevalence of a single sphenoid sinus was noted by Dündar et al. [10] - 2.2\% (5/218) and Kapur et al. [28] $-2 \%$. Hamid et al. [17] state even higher frequency of the said variant $-10.8 \%$ (32/296). The aforementioned differences might possibly be attributed to the research group studied (all the patients suffered from pituitary adenoma), as 
Table 3. Prevalence of a single sphenoid sinus

\begin{tabular}{lc}
\hline Author (materials and methods) & $\begin{array}{c}\text { Single sphenoid sinus: } \\
\text { no main septum present }\end{array}$ \\
\hline Aydinlioglu and Erdem (1526 CT) & $0.13 \%$ \\
Seddighi et al. (64 CT and MRI) & $0 \%$ \\
Abdullah et al. (70 CT) & $0 \%$ \\
Tan and Ong (48 skulls, endoscopic & $0 \%$ \\
and cadaveric study) & \\
Hammer and Radberg (120 skull X-ray & $0 \%$ \\
and CT images and 103 X-ray images) & $1.3 \%$ \\
Battal et al. (314 angio-CT) & $2.2 \%$ \\
Dündar et al. (218 CT) & $2 \%$ \\
Kapur et al. (200 CT) & $10.8 \%$ \\
Hamid et al. (296 CT and MRI) & $16 \%$ \\
Awadalla et al. (Gr. A: 25 skulls, & \\
cadaveric study) & $13 \%$ \\
Awadalla et al. (Gr. B: 364 CT and/or MRI) & $13.2 \%$ \\
ELKammash et al. (182 CT and MRI) & $0.33 \%$ \\
Jaworek-Troć et al. (300 CT) & \\
\hline
\end{tabular}

CT — computed tomography; MRI — magnetic resonance imaging

well as the ethnicity of the patients (all patients were of Egyptian origin). Yet higher results were found by Awadalla et al. [4], noted for the two different study groups: group A - cadaveric evaluation of 25 skulls (the main septum was absent in 16\%) and group $B$ - radiologic evaluation (CT and/or MRI) of 364 patients (the main septum was absent in 13\%). The said results pertain to the people of Egyptian origin and are akin to the one provided by Hamid et al. [17] for the same ethnic group. Moreover, ELKammash et al. [13] also studied the same population (182 CT and MRI scans in the Egyptians) and determined the main septum to be absent in $13.2 \%$ (Table 3 ).

Similarly to the agenesis of the sphenoid sinuses, there were no statistically significant differences between gender and prevalence of a single sphenoid sinus found in the present study $(p=0.498)$. Battal et al. [6] did not find any statistically significant differences between the numbers of septa and gender overall; however, they did not specify it for the single sphenoid sinus variant only. Likewise, it is possible that studies conducted on a larger sample of patients (counting in thousands) could potentially point towards the sex predilection of the said variant, as its prevalence is rare $(0.33 \%$ in the current study).

Undoubtedly, adequate level of pneumatisation of the sphenoid sinuses is crucial in order to perform the transnasal transsphenoidal approach for the pituitary surgery. Should agenesis of the sinuses or the conchal (foetal) type of aeration be present, the said surgical approach might prove troublesome and posing a higher risk to the patient, as it would require drilling through the bone, potentially leading to iatrogenic injuries to the nearby neurovascular structures [5]. Nonetheless, extensive pneumatisation of the sphenoid sinuses could also make the procedure prone to iatrogenic complications, but definitely facilitates surgical access [21]. There are reports in the available literature of agenesis and/or hypoplasia of a few paranasal sinuses in a single patient $[15,16,30]$; however, those are single cases and more large-scale studies ought to be performed in order to confirm or reject their potential association. Virtual dissection tables might become the future of anatomic evaluation of more complex variants [32], but conventional methods of imaging of the sphenoidal region still finds its use in orthodontics [31].

Aydinlioglu et al. [5] performed a study in 1,526 patients, presenting with a headache or undergoing diagnostic tests for possible sinusitis. We would like to acknowledge the aforementioned authors in saying that due to the agenesis of sphenoid sinuses being a rare variant, attributing its presence to extensive experience of symptoms (such as headache, infections) is yet to be determined on a larger and more varied group of patients [5].

In 2 out of 3 cases reported by Degirmenci et al. [9], sinusitis of different paranasal sinuses was found in addition to the agenesis of the sphenoid sinuses. It raises a question to the level of insufficiency of the ostiomeatal complex caused by the absence of sphenoid sinuses, and the subject definitely requires further research.

Eggesbø et al. [12] concluded that for the cystic fibrosis patients the pneumatisation of the sphenoid sinuses does not reach beyond the presphenoidal area, and medical professionals who have found the aeration in the basisphenoidal area ought to reconsider the diagnosis of cystic fibrosis. Nonetheless, the said authors did not find any agenesis of the sphenoid sinuses neither in the study group, nor the controls [12]. Sharma et al. [30] report a case with a bilateral agenesis of both frontal and sphenoid sinuses in a patient with Kartagener's syndrome. Whilst there is still need for more studies regarding this topic across various populations, this concept raises an interesting question whether the agenesis of the sphenoid sinuses and / or their hypoplasia is a result of the defected 
cilia; hence, possibly patients with other ciliary defects ought to be included in future study groups.

\section{CONCLUSIONS}

The absence of the sphenoid sinuses is a relatively rare variant, found in approximately $1 \%$. A single sphenoid sinus, with the main septum absent, was noted only in $0.33 \%$ of the patients. Acquaintance with those variants (however rare) is of dire importance to medical professionals performing transsphenoidal surgical procedures. Nonetheless, there is still need for new reliable, large-scale studies that would attempt to correlate the agenesis of the sphenoid sinuses with potential clinical symptoms, as well as look into the potential cause and effect of ciliary defects.

\section{Acknowledgements}

The authors would like to express their sincere gratitude to Mr Jacenty Urbaniak for the technical support.

\section{Conflict of interest: None declared}

\section{REFERENCES}

1. Abdullah BJ, Arasaratnam A, Kumar G, et al. The sphenoid sinuses: computed tomographic assessment of septation, relationship to the internal carotid arteries and sidewall thickness in the Malaysian population. Hong Kong J Radiol. 2001; 4: 185-188.

2. Anik I, Anik Y, Koc K, et al. Agenesis of sphenoid sinuses. Clin Anat. 2005; 18(3): 217-219, doi: 10.1002/ca.20096, indexed in Pubmed: 15768410.

3. Antoniades K, Vahtsevanos K, Psimopoulou M, et al. Agenesis of sphenoid sinus. Case report. ORL J Otorhinolaryngol Relat Spec. 1996; 58(6): 347-349, doi: 10.1159/000276868, indexed in Pubmed: 8958546.

4. Awadalla AM, Hussein Y, ElKammash TH. Anatomical and radiological parameters of the sphenoidal sinus among Egyptians and its impact on sellar region surgery. Egypt J Neurosurg. 2015; 30(1): 1-12.

5. Aydinlioğlu A, Erdem S. Maxillary and sphenoid sinus aplasia in Turkish individuals: a retrospective review using computed tomography. Clin Anat. 2004; 17(8): 618-622, doi: 10.1002/ca.20026, indexed in Pubmed: 15495178

6. Battal B, Akay S, Karaman B, et al. The Relationship between the Variations of Sphenoid Sinus and Nasal Septum. Gulhane Med J. 2014; 56(4): 232, doi: 10.5455/ gulhane.173275.

7. Cakur B, Sümbüllü MA, Yılmaz AB. A retrospective analysis of sphenoid sinus hypoplasia and agenesis using dental volumetric CT in Turkish individuals. Diagn Interv Radiol. 2011; 17(3): 205-208, doi: 10.4261/1305-3825.DIR.330410.1, indexed in Pubmed: 20698004.

8. Carvey M, Baek W, Hage R. Bridging the divide: the widening gap between basic science and clinical research.
Transl Res Anat. 2021; 24: 100117, doi: 10.1016/j. tria.2021.100117.

9. Degirmenci B, Haktanir A, Acar M, et al. Agenesis of sphenoid sinus: three cases. Surg Radiol Anat. 2005; 27(4): 351-353, doi: 10.1007/s00276-005-0336-5, indexed in Pubmed: 16200385.

10. Dündar R, Kulduk E, Soy FK, et al. Radiological evaluation of septal bone variations in the sphenoid sinus. J Med Updates. 2014; 4(1): 6-10, doi: 10.2399/jmu.2014001002.

11. Earwaker J. Anatomic variants in sinonasal CT. Radiographics. 1993; 13(2): 381-415, doi: 10.1148/radiographics.13.2.8460226, indexed in Pubmed: 8460226 .

12. Eggesbø HB, Eken T, Eiklid K, et al. Hypoplasia of the sphenoid sinuses as a diagnostic tool in cystic fibrosis. Acta Radiol. 1999; 40(5): 479-485, doi: 10.3109/02841859909175571, indexed in Pubmed: 10485235.

13. ELKammash T, Enaba M, Awadalla A. Variability in sphenoid sinus pneumatization and its impact upon reduction of complications following sellar region surgeries. Egypt J Radiol Nuclear Med. 2014; 45(3): 705-714, doi: 10.1016/j.ejrnm.2014.04.020.

14. Elwany $S$, Yacout $Y M$, Talaat $M$, et al. Surgical anatomy of the sphenoid sinus. J Laryngol Otol. 1983; 97(3): 227-241, doi: 10.1017/s0022215100094056, indexed in Pubmed: 6833847.

15. Güven DG, Yilmaz $S$, Ulus $S$, et al. Combined aplasia of sphenoid, frontal, and maxillary sinuses accompanied by ethmoid sinus hypoplasia. J Craniofac Surg. 2010; 21(5): 1431-1433, doi: 10.1097/SCS.0b013e3181ecc2d9, indexed in Pubmed: 20856033.

16. Haktanir A, Acar M, Yucel A, et al. Combined sphenoid and frontal sinus aplasia accompanied by bilateral maxillary and ethmoid sinus hypoplasia. Br J Radiol. 2005; 78(935): 1053-1056, doi: 10.1259/bjr/38163950, indexed in Pubmed: 16249610.

17. Hamid O, El Fiky L, Hassan O, et al. Anatomic Variations of the Sphenoid Sinus and Their Impact on Trans-sphenoid Pituitary Surgery. Skull Base. 2008; 18(1): 9-15, doi: 10.1055/s-2007-992764, indexed in Pubmed: 18592020.

18. Hammer G, Radberg C. The sphenoidal sinus: an anatomical and roentgenologic study with reference to transsphenoid hypophysectomy. Acta Radiol. 2013; 56(6): 401-422, doi: $10.1177 / 028418516105600601$.

19. Jaworek-Troć J, Iwanaga J, Chrzan R, et al. Anatomical variations of the main septum of the sphenoidal sinus and its importance during transsphenoidal approaches to the sella turcica. Transl Res Anat. 2020; 21: 100079, doi: 10.1016/j.tria.2020.100079.

20. Jaworek-Troć J, Walocha JA, Chrzan R, et al. Protrusion of the carotid canal into the sphenoid sinuses: evaluation before endonasal endoscopic sinus surgery. Folia Morphol. 2021; 80(3): 642-649, doi: 10.5603/FM.a2020.0086, indexed in Pubmed: 32789847.

21. Jaworek-Troć J, Walocha JA, Loukas M, et al. Extensive pneumatisation of the sphenoid bone - anatomical investigation of the recesses of the sphenoid sinuses and their clinical importance. Folia Morphol. 2020 [Epub ahead of print], doi: 10.5603/FM.a2020.0120, indexed in Pubmed: 33084012.

22. Jaworek-Troć J, Walocha JA, Skrzat J, et al. A computed tomography comprehensive evaluation of the ostium of the 
sphenoid sinus and its clinical significance. Folia Morphol. 2021 [Epub ahead of print], doi: 10.5603/FM.a2021.0063, indexed in Pubmed: 34219216.

23. Jaworek-Troć J, Zarzecki M, Bonczar A, et al. Sphenoid bone and its sinus - anatomo-clinical review of the literature including application to FESS. Folia Med Cracov. 2019; 59(2): 45-59, indexed in Pubmed: 31659348.

24. Jaworek-Troć J, Zarzecki M, Lusina D, et al. Incorporation of the sphenoid sinuses' septum / septa in the carotid canal: evaluation before the FESS. Folia Med Cracov. 2020; 60(4): 65-78, indexed in Pubmed: 33821852.

25. Jaworek-Troć J, Zarzecki M, Mróz I, et al. The total number of septa and antra in the sphenoid sinuses - evaluation before the FESS. Folia Med Cracov. 2018; 58(3): 67-81, doi: 10.24425/fmc.2018.125073, indexed in Pubmed: 30521512.

26. Jaworek-Troć J, Zarzecki M, Zamojska I, et al. The height and type of the main septum in the sphenoid sinuses: evaluation before the fess. Folia Med Crac. 2020; 60(3): 65-74, doi: 10.24425/fmc.2020.135796, indexed in Pubmed: 33582746.

27. Jaworek-Troć J, Zarzecki M, Zamojska I, et al. The dimensions of the sphenoid sinuses: evaluation before the functional endoscopic sinus surgery. Folia Morphol. 2021; 80(2): 275-282, doi: 10.5603/FM.a2020.0059, indexed in Pubmed: 32488857.

28. Kapur E, Kapidžić A, Kulenović A, et al. Septation of the sphenoid sinus and its clinical significance. Int J Coll Res Int Med Public Health. 2012; 4(10): 1793-1802.

29. Seddighi A, Seddighi AS, Mellati O, et al. Sphenoid sinus: anatomic variations and their importance in trans-sphenoid surgery. Int Clin Neurosci J. 2014; 1(1): 31-34.

30. Sharma S, Durgaprasad BK, Vijayalakshmi P. A case of Kartagener's syndrome with combined aplasia of frontal and sphenoid sinuses and hypoplasia of maxillary and ethmoid sinuses. J Family Community Med. 2021; 28(2): 129-132, doi: 10.4103/jfcm.JFCM_304_20, indexed in Pubmed: 34194278.

31. Sinha S, Shetty A, Nayak K. The morphology of Sella Turcica in individuals with different skeletal malocclusions: a cephalometric study. Transl Res Anat. 2020; 18: 100054, doi: 10.1016/j.tria.2019.100054.

32. Stecco A, Boccafoschi F, Falaschi Z, et al. Virtual dissection table in diagnosis and classification of Le Fort fractures: A retrospective study of feasibility. Transl Res Anat. 2020; 18: 100060, doi: 10.1016/j.tria.2019.100060.

33. Tan HKK, Ong YK. Sphenoid sinus: an anatomic and endoscopic study in Asian cadavers. Clin Anat. 2007; 20(7): 745750, doi: 10.1002/ca.20507, indexed in Pubmed: 17583590.

34. Tesfaye S, Hamba N, Gerbi A, et al. Radio-anatomic variability in sphenoid sinus pneumatization with its relationship to adjacent anatomical structures and their impact upon reduction of complications following endonasal transsphenoidal surgeries. Transl Res Anat. 2021; 24: 100126, doi: 10.1016/j.tria.2021.100126.

35 . Vidić $B$. The postnatal development of the sphenoidal sinus and its spread into the dorsum sellae and posterior clinoid processes. Am J Roentgenol Radium Ther Nucl Med. 1968; 104(1): 177-183, doi: 10.2214/ajr.104.1.177, indexed in Pubmed: 5672763.

36. Yonetsu K, Watanabe M, Nakamura T. Age-related expansion and reduction in aeration of the sphenoid sinus: volume assessment by helical CT scanning. Am J Neuroradiol. 2000; 21(1): 179-182, indexed in Pubmed: 10669247.

37. Yune HY, Holden RW, Smith JA. Normal variations and lesions of the sphenoid sinus. Am J Roentgenol Radium Ther Nucl Med. 1975; 124(1): 129-138, doi: 10.2214/ ajr.124.1.129, indexed in Pubmed: 167598. 